\title{
A study to evaluate the safety of platelet-derived growth factor for treatment of osteochondral defects of the talus
}

\author{
Alastair Younger $\cdot$ Kevin Wing • Murray Penner • \\ Mark Cresswell
}

Received: 30 April 2014 / Accepted: 24 February 2015 / Published online: 22 March 2015

(c) The Author(s) 2015. This article is published with open access at Springerlink.com

\begin{abstract}
Purpose An arthroscopic procedure for the treatment of osteochondral defects using platelet-derived growth factor (PDGF) carried out in a matrix of tricalcium phosphate was developed. This prospective, case-series-based study was designed to evaluate the safety and clinical utility of this procedure.

Methods Patients with an isolated osteochondral defect larger than $5 \mathrm{~mm}$ long, $3 \mathrm{~mm}$ wide, and $5 \mathrm{~mm}$ deep and smaller than $30 \mathrm{~mm}$ long, $25 \mathrm{~mm}$ wide, or $20 \mathrm{~mm}$ deep were considered for enrolment. Only patients with chronic lesions were enroled. Arthroscopic debridement was followed by the placement of recombinant human PDGF in a matrix of tricalcium phosphate. The Ankle Osteoarthritis Scale (AOS), visual analogue scale (VAS) for pain, and SF-36 questionnaires were administered at 0, 2, 6, 12, and 24 weeks. Magnetic resonance imaging (MRI) and computed tomography (CT) scans were taken before and after surgery.
\end{abstract}

\footnotetext{
A. Younger $(\square)$

Department of Orthopedics, University of British Columbia,

560 - 1144 Burrard Street, Vancouver, BC V6Z 2A5, Canada

e-mail: asyounger@shaw.ca
}

\section{K. Wing $\cdot$ M. Penner}

Department of Orthopaedics, University of British Columbia,

1000 - 1200 Burrard Street, Vancouver, BC V6Z 2C7, Canada

e-mail: kwing@vbjc.ca

M. Penner

e-mail: penner@vbjc.ca

\section{Cresswell}

Department of Radiology, University of British Columbia,

St. Paul's Hospital - 1081 Burrard Street, Vancouver,

BC V6Z 1Y6, Canada

e-mail: markcress@gmail.com
Results Five patients were ultimately enroled in this proof-of-concept trial. All outcome measures demonstrated marked improvement from baseline to final follow-up: The mean weight bearing VAS pain score improved by $49 \%$, and the mean AOS functional score improved by $28 \%$. Bone healing was seen on $\mathrm{CT}$, and reduction in oedema signal was seen on MRI.

Conclusion This new procedure may offer a promising alternative for the treatment of osteochondral defects. Further high-quality studies are needed to confirm these results and to analyse the long-term effects of the procedure. The clinical relevance of this study is that the procedure may provide a less invasive option with improved bone healing compared to standard techniques.

Level of evidence IV.

Keywords Osteochondral defect - OCD - Osteochondritis dissecans · Platelet-derived growth factor · PDGF · Bone regeneration · Arthroscopic debridement

\section{Introduction}

The initial surgical treatment for osteochondral defect (OCD) of the talus is usually arthroscopic debridement via curettage. However, many patients do not achieve adequate pain relief or restoration of mobility with debridement alone [34, 36]. In addition, even among those patients for whom debridement appears to be effective, symptoms often recur over time.

For these patients, standard treatments include osteoarticular autograft (or allograft) transfer (OATS) [18, 19], or autologous chondrocyte implantation (ACI) [2, 3, 14, 17, 25]. These open procedures are more invasive and often more expensive than arthroscopy and can result in 
considerable morbidity. In addition, debridement does not repair the underlying bone defect [15] and may thus allow continued progression of the lesion [36].

Researchers have sought treatment alternatives for OCD that could stabilise the interior of the lesion and prevent further collapse [1, 2, 7]. This report introduces a new arthroscopic procedure in which a volume-filling, osteoconductive material containing a diffusible growth factor is inserted into the OCD lesion to stimulate repair of the patient's own subchondral bone. This growth factor, recombinant human platelet-derived growth factor (rhPDGF), has been found to promote healing; regeneration; and repair of bone, ligament, periodontal cementum, and other tissues [9, 22-24, 26-33, 35].

In this new procedure, arthroscopic debridement to stable, viable bone is followed by arthroscopic placement of rhPDGF mixed with an osteoconductive matrix of beta-tricalcium phosphate $(\beta-\mathrm{TCP})$. The defect is then sealed with fibrin glue, and the patient is kept non-weight bearing for 6 weeks prior to being remobilised.

The primary objective of this case-series-based study was to evaluate the initial safety, efficacy, and clinical utility of rhPDGF/ $\beta$-TCP as an arthroscopic treatment following debridement for OCD of the talus, over the course of an initial 6-month follow-up. The hypothesis was that the procedure would result in improved pain and functional scores for patients with and OCD. The clinical relevance of this study is that, if successful, the procedure could provide a less invasive option with improved healing compared to standard techniques.

\section{Materials and methods}

This single-site, single-surgeon, prospective study, conducted with enrolment from February 2012 until November 2012, was designed as a case-series-based clinical study.

Patients diagnosed with a talar OCD were recruited for the study from the clinical practice of the authors. Inclusion criteria included signed REB-approved informed consent form (ICF) prior to enrolment; diagnosis of an isolated OCD larger than $5 \mathrm{~mm}$ long, $3 \mathrm{~mm}$ wide, and $5 \mathrm{~mm}$ deep, confirmed by MRI; independent, ambulatory and can comply with all post-operative evaluations and visits; $\geq 21$ years of age or older; skeletally mature; stable ankle joint on history and similar ligament stability with the opposite ankle; $<15^{\circ}$ of hindfoot valgus and $5^{\circ}$ of hindfoot varus; OCD is chronic and not secondary to acute trauma within the previous 6 months; if history of fracture, no residual deformity of the tibia, fibula, or syndesmosis; no prior fusions of the hindfoot (subtalar and talonavicular joints); body mass index (BMI) $\leq 35$; American Society of Anesthesiologists (ASA) physical status classification of
1 or 2; and has exhausted non-operative treatment. Exclusion criteria included $>15^{\circ}$ of hindfoot valgus or $5^{\circ}$ of hindfoot varus; defect $>30 \mathrm{~mm}$ length, $25 \mathrm{~mm}$ width, or $20 \mathrm{~mm}$ depth in size on MRI assessment; allergy to yeast-derived products; has metallic or electronically, magnetically, or mechanically activated implants that would contraindicate MRI scans of the foot; history of malignancy anywhere in the body; physically or mentally compromised and unable or unlikely to remain compliant to follow-up; history of drug/alcohol abuse within the 12 months prior to screening for study entry; pregnant, or able to become pregnant but not practicing a medically accepted form of birth control; current acute infection in area surrounding surgical site; history of anaphylaxis; condition is bilateral and surgery is to be scheduled over the course of the study; requires concomitant osteotomy of tibia, fibula, or calcaneus for hindfoot deformity, or requires concomitant hindfoot fusion for hindfoot arthritis or deformity; undergoing any concomitant surgery that may invalidate outcome scores for this study; OCD of the tibia in isolation or in combination with the talar lesion; nicotine addiction or using medication or substances containing nicotine; cocaine abuse or use of cocaine derivatives; undergoing revision debridement of an OCD.

\section{Data collection}

Diagnosis of OCD was confirmed via baseline magnetic resonance imaging (MRI) scans of the lesion site prior to enrolment. Location and size of defect (width, depth, and length), were determined via ankle arthroscopy and recorded prior to treatment. Photographs of defect before and after debridement as well as any associated pathology (osteophytes, synovitis) were also obtained.

Patient demographics, comorbidities, and diagnoses were recorded preoperatively. Patient assessments were completed preoperatively and at 2, 6, 12, and 24 weeks post-operatively. Clinical outcomes were recorded preoperatively and at each follow-up visit using the visual analogue scale (VAS) for pain [21], the Ankle Osteoarthritis Scale (AOS) [11], the short-form-36 (SF-36) Health Survey [6], and AP and lateral X-rays. All adverse events affecting the ankles were also recorded at each study visit (see "Appendix").

Follow-up MRI was conducted at 12 and 24 weeks, in order to evaluate bone marrow oedema. In addition, CT scans at 2 and 24 weeks were compared in order to determine healing status at the base of the OCD and fill of the graft. All scans were measured using InteleViewer software tools (Intelerad, Calgary, AB, Canada), which enable automated, quantitative segmentation and calculation of two-dimensional area and three-dimensional volume measurements (with read-outs in $1-\mathrm{mm}$ increments), as well as image registration for pre- and 
post-treatment comparisons of patient lesions. The MRI scans were evaluated with sagittal and coronal sequences cut with the greatest amount of oedema (T2-weighted signal on fat suppressed images) being measured for square surface area of involvement. The oedema signal was measured preoperatively and at each follow-up period. The total area in square millimetres was analysed using the analysis of variance. The CT scan was evaluated for size of defect preoperatively and for fill with bone graft at both time periods. The CT was measured on one $0.6-\mathrm{mm}$ slice on the sagittal view and one $0.6-\mathrm{mm}$ slice on the coronal view.

\section{Surgical techniques}

All procedures were performed by a single surgeon having advanced skills in arthroscopy and foot and ankle surgery. Patients were treated with arthroscopic debridement of the OCD to stable, viable bone via abrasive osteochondroplasty without microfracture or drilling. (Microfracture was not used because the subchondral bone was breached and softened in all cases). Debridement was followed by arthroscopic placement of a preparation containing rhPDGF and $\beta$-TCP (see below).

Routine ankle arthroscopy was performed using anterior medial, anterior lateral, and medial portals to access and debride the joint. An Augment Bone Graft preparation (BioMimetic Inc., Memphis, TN) containing $\beta$-TCP and rhPDGF was then prepared using standard techniques and placed into the joint via the arthroscopic portal. Following mixing, the final consistency of the graft material is similar to that of granular wet sand. When placed near a viable

Table 1 Dimensions of OCD lesions from arthroscopic assessment

\begin{tabular}{|c|c|c|}
\hline & Average & Standard deviation \\
\hline Length (mm) & 14 & 3 \\
\hline Width (mm) & 9 & 2 \\
\hline Depth (mm) & 11 & 2 \\
\hline Surface $\operatorname{area}^{\mathrm{a}}\left(\mathrm{mm}^{2}\right)$ & 103 & 37 \\
\hline Volume $^{\mathrm{b}}\left(\mathrm{mm}^{3}\right)$ & 285 & 139 \\
\hline
\end{tabular}

a Surface area was calculated as an ellipse

b Volume was calculated as a hemi-ellipsoid host bone, it acts as scaffold for new bone growth; it subsequently undergoes remodelling and is finally replaced by host bone [8]. All materials used in the components have been previously approved by Health Canada for the treatment of foot and ankle fusion procedures and by the FDA for the treatment of periodontal bone defects.

Fibrin glue was then placed over the defect to ensure containment of TCP granules. The foot was dorsiflexed while the fibrin glue set, then the ankle kept dorsiflexed until the wounds were closed and the limb placed in a below-the-knee slab in dorsiflexion for 2 weeks post-surgery.

If all appeared stable at 2 weeks, subjects began joint range-of-motion exercises in a walker boot and remained non-weight bearing until the 6-week follow-up visit.

\section{Outcome measures}

The primary outcome measures were the VAS for pain and the Ankle Osteoarthritis Scale (AOS). The VAS for pain is a unidimensional, self-reported measure of pain intensity [16, 20, 21], which has been widely used in diverse adult populations, including those with rheumatic disease $[12,13]$. The AOS is a reliable, validated, patient-reported, ankle-specific functional outcome instrument [11]. Both the pain and disability components were used to calculate the total AOS score. (The score ranges from 0 to 100 , with a lower score indicating more normal function). Secondary outcome measures included the physical component summary (PCS) and mental component summary (MCS) subscales of the SF-36 Health Survey questionnaire, and MRI and CT scans of the affected ankles. The SF-36 is a generic, patient-reported measure of general health status $[4,6]$ that has been shown to have acceptable criterion validity in patients with end-stage ankle arthritis [20].

This study was approved by the Institutional Review Board of the Providence Health Care Research Institute at the University of British Columbia (REB \#H03-50062) and was therefore performed in accordance with the ethical standards laid down in the 1964 Declaration of Helsinki and its later amendments. All patients provided informed consent for study enrolment and for the surgical procedure prior to questionnaire administration.

Table 2 Mean outcome scores, pain, and disability

\begin{tabular}{|c|c|c|c|c|c|c|c|}
\hline & \multicolumn{2}{|c|}{ VAS pain scale } & \multicolumn{3}{|l|}{ AOS } & \multicolumn{2}{|c|}{ SF-36 } \\
\hline & Non-WB & WB & Pain & Disability & Total & PCS & MCS \\
\hline Preoperative baseline & 3.4 & 4.1 & 37.2 & 38.2 & 37.7 & 35.1 & 53.2 \\
\hline Week 24 & 1.1 & 2.1 & 25.9 & 27.6 & 26.7 & 42.9 & 53.5 \\
\hline
\end{tabular}

VAS visual analogue scale, AOS Ankle Osteoarthritis Scale, $S F$-36 short-form (36) Health Survey, WB weight bearing, $P C S$ physical component summary, MCS mental component summary 


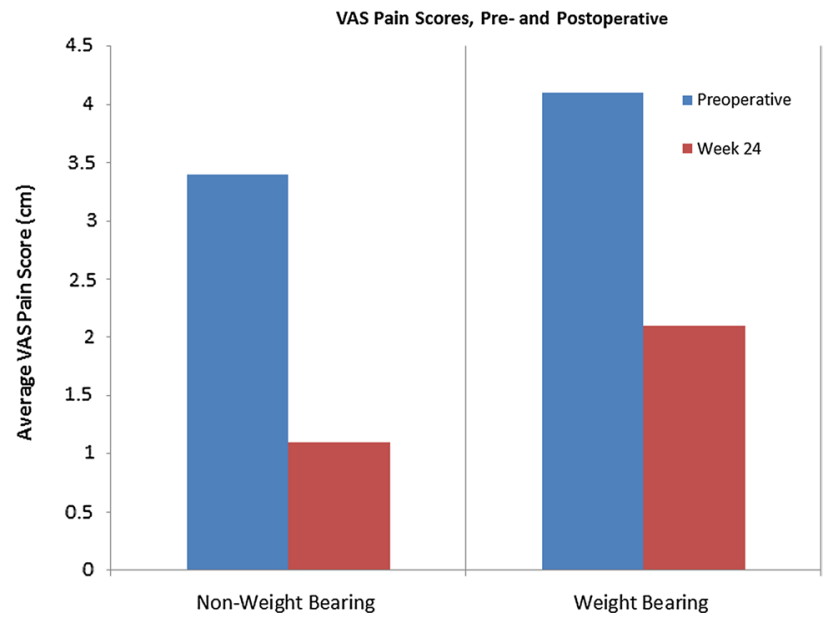

Fig. 1 Average scores on the VAS pain questionnaire, from preoperative baseline (preop) to final follow-up (week 24). A lower score indicates decreased pain

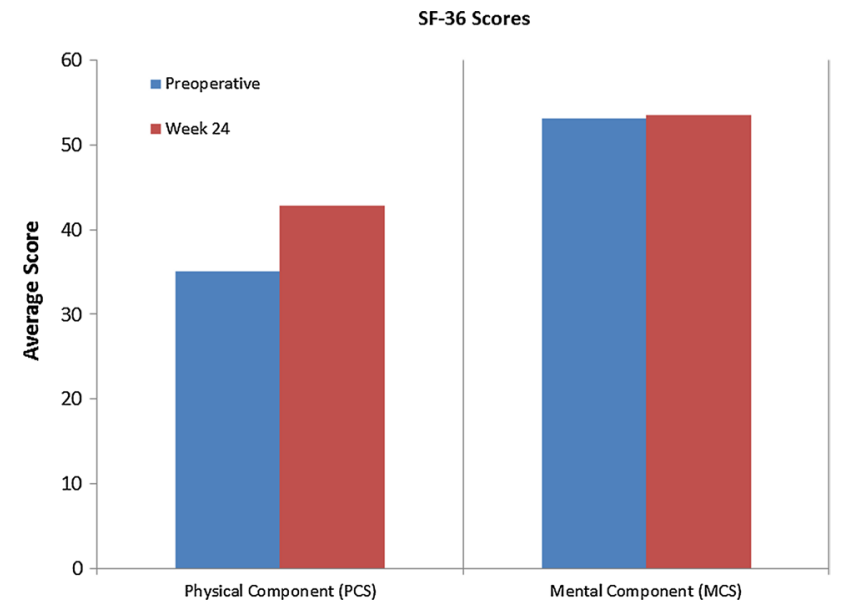

Fig. 2 Average scores on the mental and physical components of the SF-36 Health Survey questionnaire, from preoperative baseline (preop) to final follow-up (week 24). Increased scores indicate improvement
Fig. 3 Average scores on the total Ankle Osteoarthritis Scale (AOS) and on the pain and disability components, from preoperative baseline (preop) to final follow-up (week 24). Decreased scores indicate improvement

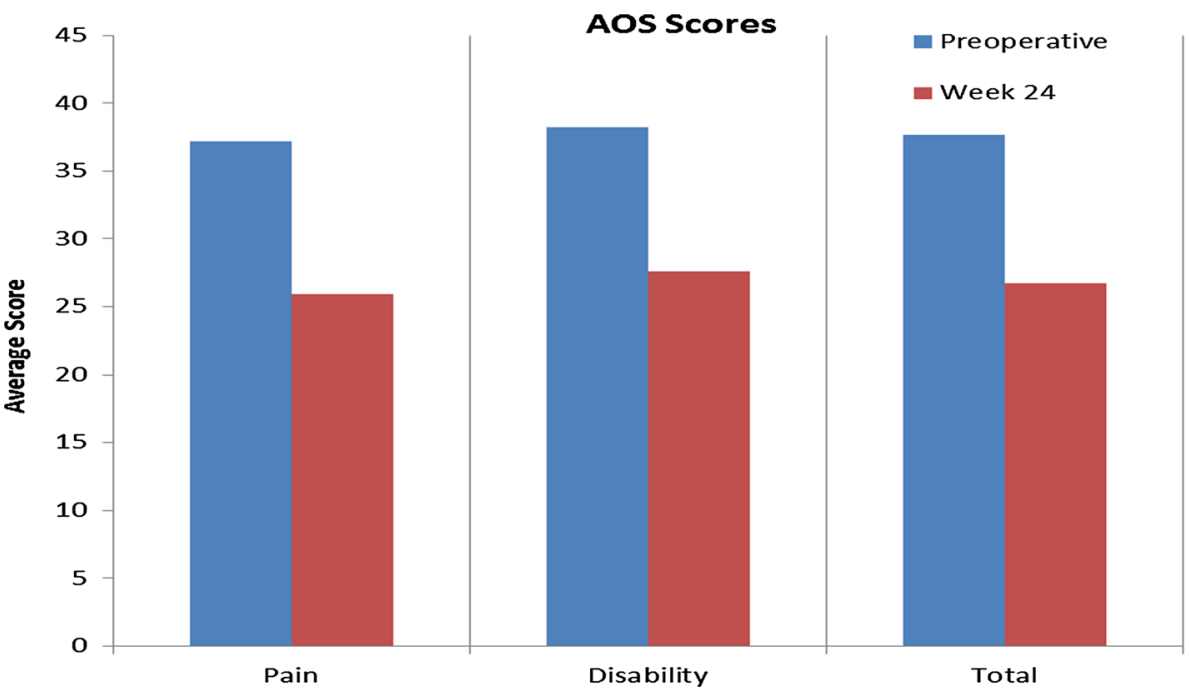

\section{Statistical analysis}

Treatment safety and efficacy were assessed by comparing the preoperative baseline scores on the primary and secondary outcome measures with the scores recorded during follow-up evaluations at 6, 12, and 24 weeks, using Student's $t$ test. Ninety-five per cent confidence intervals were used to assess variability using AOS scores and mean area of oedema $\left(\mathrm{mm}^{2}\right)$ via MRI.

\section{Results}

Thirty patients with verified OCD were initially assessed for inclusion in this pilot study. Of these, 25 patients were excluded due to ankle instability or other associated pathology, or were from the practice of another surgeon.

Five patients with six OCD lesions of the talus met all inclusion and exclusion criteria, and underwent arthroscopic debridement followed by arthroscopic filling of the defect with rhPDGF-BB/ $\beta$-TCP matrix. None of these patients withdrew from the study before the final follow-up visit at 24 weeks; all patients were seen for follow-up at the correct intervals and had complete data.

Mean patient age was $52 \pm 8.5$ years, and mean BMI was $26.3 \pm 5.0$. Three of the patients were female and two were male. In one patient, the OCD occurred in the left ankle; in the remainder, it occurred in the right ankle. One patient had two lesions on the same ankle (one on the medial and one on the lateral side of the talus). Defect 
parameters are summarised in Table 1 . Four patients had undergone a prior debridement, and three had undergone more than one prior debridement. Four lesions were shoulder lesions and two were not.

Mean scores for pain and disability at baseline and at 24 weeks post-operative follow-up (as measured by the VAS, SF-36, and AOS scales) are listed in Table 2. Changes in these scores are illustrated in Figs. 1, 2 and 3.

No major adverse events related to the graft were observed. Over the course of the study, there were no wound infections, wound breakdowns, reoperations, loss of motion, symptoms of loose body/impingement, or synovitis. (Any additional adverse events affecting the ankle are listed by patient in the "Appendix").

Table 3 Mean area of oedema $\left(\mathrm{mm}^{2}\right)$ via MRI

\begin{tabular}{lrl}
\hline Parameter & \multicolumn{1}{l}{ Preop } & 24 weeks \\
\hline Coronal oedema & 95 (CI 20-171) & 71 (CI 0-208) \\
Sagittal oedema & 140 (CI 50-229) & 37 (CI 0-93) \\
Average & 118 (CI 45-190) & 54 (CI 0-150) \\
\hline
\end{tabular}
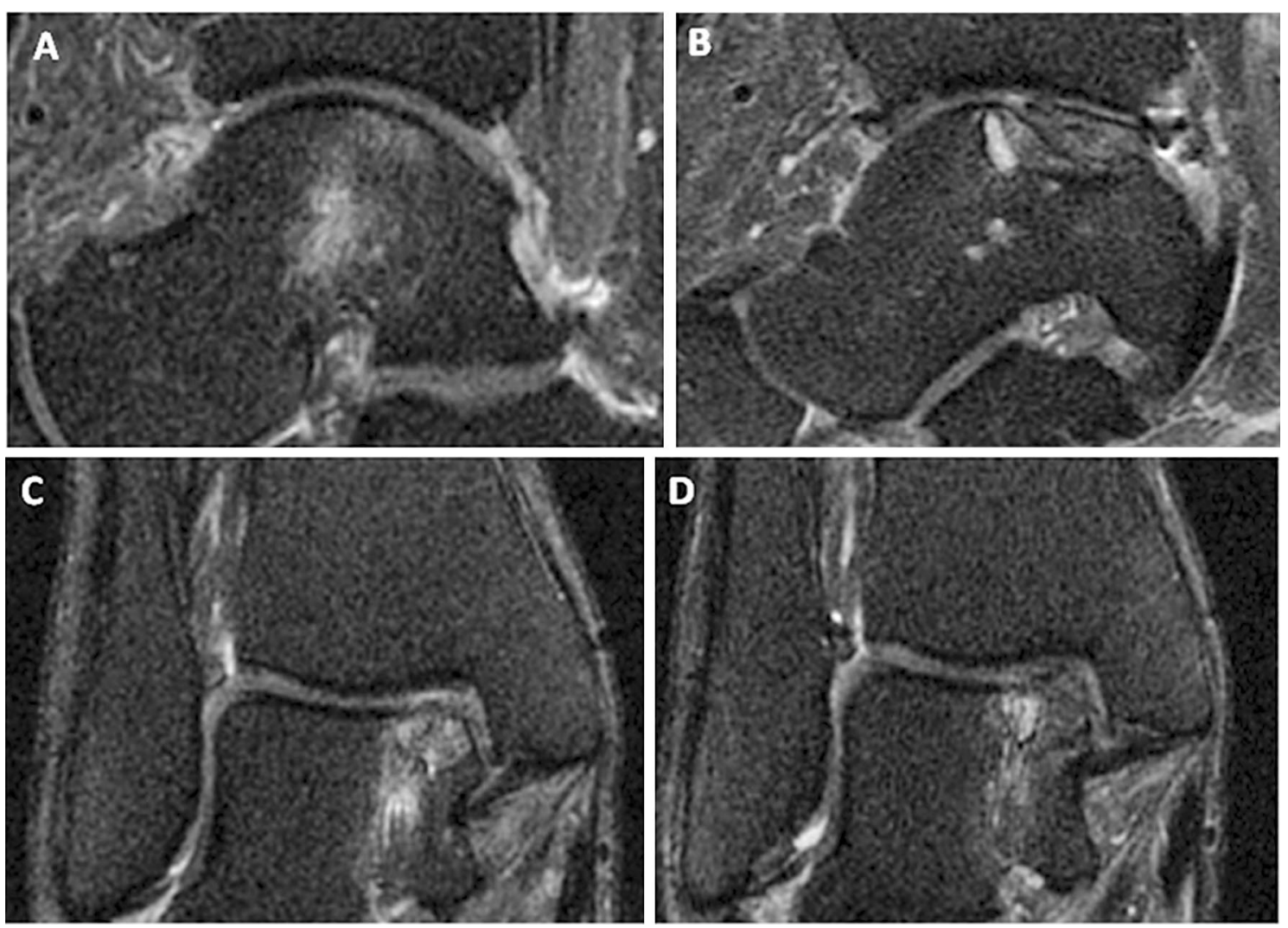

Fig. 4 Magnetic resonance imaging (MRI) scans. a Preoperative sagittal view showing bone marrow oedema. b Post-operative sagittal view showing reduction in the oedema signal. c Preoperative coronal
Evaluation of bone marrow oedema as visualised by MRI, preoperatively and at 24 weeks post-operatively, is shown in Table 3 and Fig. 4 (note that retrograde drilling was not possible in this joint, as only minimal cartilage remained).

Incorporation of the graft as visualised by $\mathrm{CT}$ scan, at 2- and 24-week follow-ups, is shown in Table 4 and Fig. 5.

\section{Discussion}

The most important finding of the present study was that a new arthroscopic procedure yielded improved pain and functional scores for patients with OCD, and enhanced healing of these lesions (as confirmed by MRI and CT scans). No short-term complications were observed despite close monitoring of the patients. This prospective, singlecentre, case-series-based, proof-of-concept study evaluated the initial safety, efficacy, and clinical utility of rhPDGF/ $\beta$ TCP as an arthroscopic treatment following debridement for OCD of the talus in five patients.

Results at 6-month follow-up indicate that the method is both safe and effective, at least initially. Mean non-weight view showing bone marrow oedema. d Post-operative coronal view showing reduced marrow signal 
Table 4 Mean area of OCD lesions and percentage filled by graft, as visualised via $\mathrm{CT}$ scan

\begin{tabular}{lll}
\hline Parameter & 2 weeks & 24 weeks \\
\hline Coronal view $\left(\mathrm{mm}^{2}\right)$ & 69 & 58 \\
Sagittal view $\left(\mathrm{mm}^{2}\right)$ & 89 & 76 \\
Amount of defect filled by graft (coronal view) $(\%)$ & 85.2 & 54 \\
Amount of defect filled by graft (sagittal view) (\%) & 84.6 & 61 \\
\hline
\end{tabular}
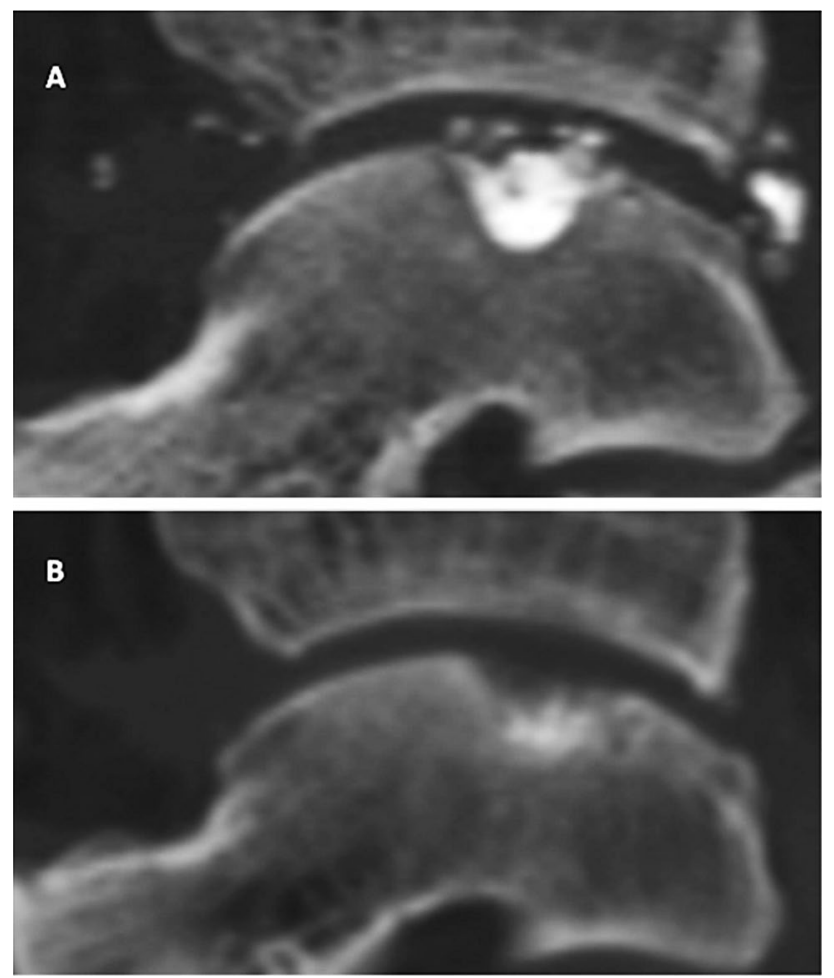

Fig. 5 Post-operative computed tomography (CT) scans. a Coronal view at 2 weeks showing fill of the osteochondral defect. b Coronal view at final scan (24 weeks) showing healing of the bone in the base of the osteochondral defect and resorption of periarticular tricalcium phosphate granules

bearing VAS pain scores decreased by $68 \%$, mean weight bearing VAS pain scores decreased by $49 \%$ (VAS), and mean scores on the AOS disability component decreased by $28 \%$ (Table 2; Figs. 1, 3). MRI scans confirmed a reduction in subchondral oedema over time in all patients, with the mean area decreasing by $25 \%$ on the coronal view and by $74 \%$ on the sagittal view from preoperative baseline to final follow-up scans at 24 weeks (Table 3; Fig. 4). No heterotopic ossification was evident on follow-up CT scans, and the graft was incorporated in all five cases (Table 4; Fig. 5). In addition, no major adverse events related to the graft were observed, and none of the patients required reoperation for their OCD.
With procedures such as OATS, not only is there increased risk of knee donor-site morbidity [19], but the force of impact during graft insertion can damage both the talus and the chondrocytes in the graft [5]. Thus, gentler insertion of the non-cellular preparation used in our procedure confers the added advantage of reduced damage to ankle and graft, as well as the knee.

In a large, multi-centre, prospective, randomised, controlled, clinical trial, DiGiovanni et al. [10] compared the safety and efficacy of PDGF/ $\beta$-TCP versus autogenous bone grafts (autografts) in patients requiring hindfoot or ankle fusion. The study found that the PDGF treatment resulted in comparable fusion rates, less pain, and fewer side effects compared to treatment with autograft. Due to its role as a mitogenic and chemotactic factor for fibroblasts [30, 32], osteoblasts [22-24, 26, 29], chondrocytes [28, 33], and tenoblasts [9, 27, 35], PDGF also holds considerable promise in restoring bone integrity in lesions such as OCDs. Healing and restoration of the subchondral bone may thus make our method more effective in the long term than cartilage grafts, OATS, or ACI. In addition, this new procedure offers an alternative that should prove to be less invasive and more economical than either OATS or ACI.

The current study has several strengths. Its prospective design provides proof of concept in support of the original hypothesis. Especially promising was the fact that four of the five patients had undergone previous debridements that required revision, but no revisions or additional procedures were required following the $\mathrm{rhPDGF} / \beta-\mathrm{TCP}$ treatment. Limitations included small sample size, a short follow-up period, lack of a concurrent control group, and potential selection bias due to patient recruitment from a single clinical centre. In addition, the improved area of marrow oedema observed at final follow-up could be due in part to a period of relatively limited mobility. A larger, multi-centre, randomised, controlled trial with a minimum 2-year follow-up period is needed and is planned in order to address these limitations.

The clinical relevance of this study is that it demonstrates that a new technique using a human growth factor for the treatment of OCD can be safe, well tolerated, and clinically useful. If the results of the present study are confirmed in a larger trial, the potential benefits include lower cost, less post-operative pain, fewer wound complications, and shorter recovery time due to its less invasive nature; no non-unions of osteotomies; considerable reductions in patient-reported pain several months after surgery; and better long-term outcomes, compared with more invasive procedures such as OATS or ACI, which are currently the standard of care. In addition, there is no need for grafts (and therefore no donor-site morbidity), and this mixture of growth factor and osteoconductive matrix may help to 
stabilise the lesion after debridement, preventing further progression.

\section{Conclusion}

In conclusion, the use of rhPDGF in an osteoconductive matrix shows promise as a clinically useful alternative for the treatment of OCD lesions of the talus following arthroscopic debridement. An expanded series or randomised, controlled trial is required to confirm these results.

Acknowledgments The authors wish to thank Biraj Bora and his research office team for invaluable assistance in coordinating this research, and Katherine Austin for editorial assistance in the preparation of this manuscript.
Conflict of interest None of the authors have received financial support, including pharmaceutical company support, for authorship, or promotion of this study. The study was funded by BioMimetic Inc. via an investigator initiated study agreement through the University of British Columbia. AY has received previous research funding for product evaluation from BioMimetic Inc.

Open Access This article is distributed under the terms of the Creative Commons Attribution License which permits any use, distribution, and reproduction in any medium, provided the original author(s) and the source are credited.

\section{Appendix: adverse events}

See Tables 5, 6, and 7 .

Table 5 Adverse events as reported by patients

\begin{tabular}{|c|c|c|}
\hline Patient ID & Adverse event description & Onset date \\
\hline \multirow[t]{9}{*}{001} & Fell using crutches, stuck splint at study ankle & 12 March 2012 \\
\hline & Slipped on stairs, muscles sore at ankle & 11 May 2012 \\
\hline & $\begin{array}{l}\text { Development of stress fracture at calcaneus of study foot (osteoporosis-Z- } \\
\text { score-3.7, severely osteoporotic) }\end{array}$ & Noted during May 2012 \\
\hline & Small clot with superficial phlebitis right ankle & Noted during 17 May 2012 appointment \\
\hline & Severed ACL right leg (study side) & Noted during unscheduled visit 18 July 2012 \\
\hline & Fell off bike, landed on right side (knee area) & Early August 2012 \\
\hline & Occasional catching and locking symptoms study ankle & Noted during 24 August 2012 visit \\
\hline & Medial pain, study ankle & Noted during 24 August 2012 visit \\
\hline & Dropped 1-lb weight on study ankle & Noted during 24 August 2012 visit \\
\hline \multirow[t]{2}{*}{002} & Right hip replacement & 6 March 2013 \\
\hline & $\begin{array}{l}\text { Continued pain left study ankle. Bony prominence subtalar joint noted during } \\
\text { May } 9 \text { follow-up-patient had injection for this }\end{array}$ & Noted during unscheduled visit 4 April 2013 \\
\hline \multirow[t]{7}{*}{003} & Cast causing pain—removed and replaced & Noted during unscheduled visit 23 October 2012 \\
\hline & Sharp, acute pain right study ankle & 5 November 2012 \\
\hline & $\begin{array}{l}\text { Shooting pains medial ankle, decreased sensation throughout entire dorsum of } \\
\text { foot }\end{array}$ & Noted during 15 November 2012 visit \\
\hline & $\begin{array}{l}\text { Patient notes colour difference right study ankle, swelling in foot, lump on botto } \\
\text { of foot (noticed during December 2012), sore big toe with pain radiating to foc } \\
\text { numbness }\end{array}$ & Noted during unscheduled visit 21 December 2012 \\
\hline & Severe OA left knee—referred to specialist & Referral 27 December 2012 \\
\hline & After short walk, sharp pain in ankle & 6 January 2013 \\
\hline & Corneal surgery for displaced lens & 10 January 2013 \\
\hline \multirow[t]{3}{*}{004} & Graft not contained as well as hoped & Noted during 7 June 2012 visit \\
\hline & Stiff ankle & Noted during 12 July 2012 \\
\hline & Ankle becomes swollen after running any distance & Noted during 15 November 2012 visit \\
\hline \multirow[t]{5}{*}{005} & Slipped in elevator, caught himself & 24 June 2012 \\
\hline & Patient notes occasional numb/tingling sensation & Noted during 25 June 2012 visit \\
\hline & Residual material back of joint & Noted during 25 June 2012 visit \\
\hline & Dropped brick on ankle & 16 August 2012 \\
\hline & $\begin{array}{l}\text { Withdrawal symptoms from discontinuation of tramadol—insomnia, loss of } \\
\text { appetite }\end{array}$ & Noted during 30 August 2012 visit \\
\hline
\end{tabular}


Table 6 Adverse event definitions: severity criteria

\begin{tabular}{ll}
\hline Degree & Description \\
\hline Mild (Grade 1) & $\begin{array}{c}\text { Symptom(s) barely noticeable to subject or does not make subject uncomfortable; does not influence performance } \\
\text { or functioning; prescription drug not ordinarily needed for relief of symptom(s), but may be given because of the } \\
\text { nature of subject }\end{array}$ \\
Moderate (Grade 2) & $\begin{array}{c}\text { Symptom(s) of a sufficient severity to make subject uncomfortable; performance of daily activity is influenced; } \\
\text { subject is able to continue in study; treatment of symptom(s) may be needed }\end{array}$ \\
Severe (Grade 3) & $\begin{array}{c}\text { Cause severe discomfort; symptoms cause incapacitation or significant impact on subject's daily life; severity may } \\
\text { cause cessation of treatment with study device; treatment for symptom(s) may be given and/or subject hospitalised } \\
\text { Life-threatening (Grade 4) }\end{array}$ \\
$\begin{array}{c}\text { Extreme limitation in activity; significant assistance required; significant medical intervention/therapy required; } \\
\text { hospitalisation or hospice care required }\end{array}$ \\
\hline
\end{tabular}

Table 7 Adverse event definitions: relationship to procedure

\begin{tabular}{l} 
Relationship \\
\hline Description \\
$\begin{array}{l}\text { Unlikely } \\
\text { Any reaction that does not follow a reasonable temporal sequence from administration of the study device AND that is likely to } \\
\text { have been produced by the subject's clinical state or other modes of therapy administered to the subject } \\
\text { Any reaction that does not follow a reasonable temporal sequence from administration of the study device or that is likely to have } \\
\text { been produced by the subject's clinical state or other modes of therapy administered to the subject }\end{array}$ \\
$\begin{array}{c}\text { A reaction that follows a reasonable temporal sequence from administration of the study device OR that follows a known response } \\
\text { pattern to the suspended device AND that could not be reasonably explained by the known characteristics of the subject's clini- } \\
\text { cal state or other modes of therapy administered to the subject }\end{array}$ \\
$\begin{array}{c}\text { A reaction that follows a reasonable temporal sequence from administration of the study device AND that follows a known } \\
\text { response pattern to the suspected device AND that recurs with rechallenge, and/or is improved by removing the device }\end{array}$
\end{tabular}

\section{References}

1. Adams SB Jr, Viens NA, Easley ME, Stinnett SS, Nunley JA 2nd (2011) Midterm results of osteochondral lesions of the talar shoulder treated with fresh osteochondral allograft transplantation. J Bone Joint Surg Am 93(7):648-654

2. Agung M, Ochi M, Adachi N, Uchio Y, Takao M, Kawasaki K (2004) Osteochondritis dissecans of the talus treated by the transplantation of tissue-engineered cartilage. Arthroscopy 20(10):1075-1080

3. Anders S, Goetz J, Schubert T, Grifka J, Schaumburger J (2012) Treatment of deep articular talus lesions by matrix associated autologous chondrocyte implantation-results at five years. Int Orthop 36(11):2279-2285

4. Beaton DE, Schemitsch E (2003) Measures of health-related quality of life and physical function. Clin Orthop Relat Res 413:90-105

5. Borazjani BH, Chen AC, Bae WC, Patil S, Sah RL, Firestein GS, Bugbee WD (2006) Effect of impact on chondrocyte viability during insertion of human osteochondral grafts. J Bone Joint Surg Am 88(9):1934-1943

6. Brazier JE, Harper R, Jones NM, O'Cathain A, Thomas KJ, Usherwood T, Westlake L (1992) Validating the SF-36 health survey questionnaire: new outcome measure for primary care. BMJ 305(6846):160-164

7. Bugbee WD, Khanna G, Cavallo M, McCauley JC, Gortz S, Brage ME (2013) Bipolar fresh osteochondral allografting of the tibiotalar joint. J Bone Joint Surg Am 95(5):426-432

8. Buser D, Hoffmann B, Bernard JP, Lussi A, Mettler D, Schenk RK (1998) Evaluation of filling materials in membrane-protected bone defects. A comparative histomorphometric study in the mandible of miniature pigs. Clin Oral Implants Res 9(3):137-150
9. Costa MA, Wu C, Pham BV, Chong AK, Pham HM, Chang J (2006) Tissue engineering of flexor tendons: optimization of tenocyte proliferation using growth factor supplementation. Tissue Eng 12(7):1937-1943

10. DiGiovanni CW, Lin SS, Baumhauer JF, Daniels T, Younger A, Glazebrook M, Anderson J, Anderson R, Evangelista P, Lynch SE (2013) Recombinant human platelet-derived growth factorBB and beta-tricalcium phosphate (rhPDGF-BB/beta-TCP): an alternative to autogenous bone graft. J Bone Joint Surg Am 95(13):1184-1192

11. Domsic RT, Saltzman CL (1998) Ankle osteoarthritis scale. Foot Ankle Int 19(7):466-471

12. Downie WW, Leatham PA, Rhind VM, Wright V, Branco JA, Anderson JA (1978) Studies with pain rating scales. Ann Rheum Dis 37(4):378-381

13. Emery P, Kavanaugh A, Bao Y, Ganguli A, Mulani P (2014) Comprehensive disease control (CDC): What does achieving CDC mean for patients with rheumatoid arthritis? Ann Rheum Dis. doi:10.1136/annrheumdis-2014-205302

14. Giannini S, Buda R, Grigolo B, Vannini F (2001) Autologous chondrocyte transplantation in osteochondral lesions of the ankle joint. Foot Ankle Int 22(6):513-517

15. Giannini S, Vannini F (2004) Operative treatment of osteochondral lesions of the talar dome: current concepts review. Foot Ankle Int 25(3):168-175

16. Hawker GA, Mian S, Kendzerska T, French M (2011) Measures of adult pain: visual analog scale for pain (VAS Pain), numeric rating scale for pain (NRS Pain), mcgill pain questionnaire (MPQ), short-form mcgill pain questionnaire (SFMPQ), chronic pain grade scale (CPGS), short form-36 bodily pain scale (SF-36 BPS), and measure of intermittent and constant osteoarthritis pain (ICOAP). Arthritis Care Res 63(Suppl 11):S240-S252 
17. Koulalis D, Schultz W, Heyden M (2002) Autologous chondrocyte transplantation for osteochondritis dissecans of the talus. Clin Orthop Relat Res 395:186-192

18. Kreuz PC, Steinwachs M, Erggelet C, Lahm A, Henle P, Niemeyer P (2006) Mosaicplasty with autogenous talar autograft for osteochondral lesions of the talus after failed primary arthroscopic management: a prospective study with a 4-year follow-up. Am J Sports Med 34(1):55-63

19. LaPrade RF, Botker JC (2004) Donor-site morbidity after osteochondral autograft transfer procedures. Arthroscopy 20(7):e69-e73

20. Madeley NJ, Wing KJ, Topliss C, Penner MJ, Glazebrook MA, Younger AS (2012) Responsiveness and validity of the SF-36, Ankle Osteoarthritis Scale, AOFAS Ankle Hindfoot Score, and Foot Function Index in end stage ankle arthritis. Foot Ankle Int 33(1):57-63

21. McCormack HM, Horne DJ, Sheather S (1988) Clinical applications of visual analogue scales: a critical review. Psychol Med 18(4):1007-1019

22. McGuire MK, Scheyer ET, Schupbach P (2009) Growth factormediated treatment of recession defects: a randomized controlled trial and histologic and microcomputed tomography examination. J Periodontol 80(4):550-564

23. Mellonig JT, Valderrama Mdel P, Cochran DL (2009) Histological and clinical evaluation of recombinant human platelet-derived growth factor combined with beta tricalcium phosphate for the treatment of human Class III furcation defects. Int J Periodontics Restorative Dent 29(2):169-177

24. Nevins M, Giannobile WV, McGuire MK, Kao RT, Mellonig JT, Hinrichs JE, Mcallister BS, Murphy KS, McClain PK, Nevins ML, Paquette DW, Han TJ, Reddy MS, Lavin PT, Genco RJ, Lynch SE (2005) Platelet-derived growth factor stimulates bone fill and rate of attachment level gain: results of a large multicenter randomized controlled trial. J Periodontol 76:2205-2215

25. Peterson L, Brittberg M, Lindahl A (2003) Autologous chondrocyte transplantation of the ankle. Foot Ankle Clin 8(2):291-303

26. Ridgway HK, Mellonig JT, Cochran DL (2008) Human histologic and clinical evaluation of recombinant human platelet-derived growth factor and beta-tricalcium phosphate for the treatment of periodontal intraosseous defects. Int J Periodontics Restor Dent 28(2):171-179

27. Sakiyama-Elbert SE, Das R, Gelberman RH, Harwood F, Amiel D, Thomopoulos S (2008) Controlled-release kinetics and biologic activity of platelet-derived growth factor-BB for use in flexor tendon repair. J Hand Surg Am 33(9):1548-1557

28. Schmidt MA, Chen EH, Lynch S (2005) A review of the effects of insulin-like growth factor and platelet derived growth factor on in vivo cartilage healing and repair. Osteoarthr Cartil 14:403-412

29. Shah P, Keppler L, Rutkowski J (2014) A review of platelet derived growth factor playing pivotal role in bone regeneration. $\mathrm{J}$ Oral Implantol 40(3):330-340

30. Thomopoulos S, Das R, Sakiyama-Elbert S, Silva M, Charlton N, Gelberman R (2010) bFGF and PDGF-BB for tendon repair: controlled release and biologic activity by tendon fibroblasts in vitro. Ann Biomed Eng 38(2):225-234

31. Thomopoulos S, Das R, Silva MJ, Sakiyama-Elbert S, Harwood FL, Zampiakis E, Kim HM, Amiel D, Gelberman RH (2009) Enhanced flexor tendon healing through controlled delivery of PDGF-BB. J Orthop Res 27(9):1209-1215

32. Thomopoulos S, Harwood F, Silva M, Amiel D, Gelberman R (2005) Effect of several growth factors on canine flexor tendon fibroblast proliferation and collagen synthesis in vitro. J Hand Surg Am 30A(3):441-447

33. Thomopoulos S, Zaegel M, Das R, Harwood F, Silva M, Amiel D, Sakiyama-Elbert S, Gelberman R (2007) PDGF-BB released in tendon repair using a novel delivery system promotes cell proliferation and collagen remodeling. J Orthop Res 25(10):1358-1368

34. Tol JL, Struijs PA, Bossuyt PM, Verhagen RA, van Dijk CN (2000) Treatment strategies in osteochondral defects of the talar dome: a systematic review. Foot Ankle Int 21(2):119-126

35. Weiler A, Forster C, Hunt P, Falk R, Jung T, Unterhauser FN, Bergmann V, Schmidmaier G, Haas NP (2004) The influence of locally applied platelet-derived growth factor-BB on free tendon graft remodeling after anterior cruciate ligament reconstruction. Am J Sports Med 32(4):881-891

36. Zengerink M, Struijs PA, Tol JL, van Dijk CN (2010) Treatment of osteochondral lesions of the talus: a systematic review. Knee Surg Sports Traumatol Arthrosc 18(2):238-246 